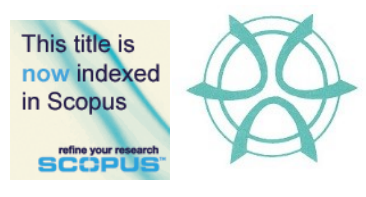

\title{
AN INTEGRATED APPROACH BASED ON ARTIFICIAL INTELLIGENCE USING ANFIS AND ANN FOR MULTIPLE CRITERIA REAL ESTATE PRICE PREDICTION
}

\author{
A. A. Yakub ${ }^{1}$, Hishamuddin, Mohd. Ali ${ }^{2}$, Kamalahasan, Achu ${ }^{3}$, Rohaya \\ binti Abdul Jalil ${ }^{4} \&$ Salawu, A.O \\ 1,2,3,4 Centre for Real Estate Studies, Faculti of Built Environment \& Surveying \\ UNIVERSITI TEKNOLOGI MALAYSIA \\ ${ }^{1 \& 5}$ Department of Estate Management, College of Built Environment, \\ HAFEDPOLY, KAZAURE, JIGAWA STATE, NIGERIA
}

\begin{abstract}
A relatively high level of precision is required in real estate valuation for investment purposes. Such estimates of value which is carried out by real estate professionals are relied upon by the end-users of such financial information having paid a certain fee for consultation hence leaving little room for errors. However, valuation reports are often criticised for their inability to be replicated by two or more valuers. Hence, stirring to a keen interest within the academic cycle leading to the need for exploring avenues to improve the price prediction ability of the professional valuer. This study, therefore, focuses on overcoming these challenges by introducing an integrated approach that combines ANFIS with ANN termed ANFIS-AN, thereby having a reiteration in terms of ANN application to fortify price predictability. Using 255 property data alongside 12 variables, the ANFIS-AN model was adopted and its outcome was compared with that of ANN. Finally, the results were subjected to 3 different error testing models using the same training and learning benchmarks. The proposed model's RMSE gave 1.413169, while that of ANN showed 9.942206. Similarly, using MAPE, ANN recorded 0.256438 while ANFIS-AN had 0.208324. Hence, ANFIS-AN's performance is laudable, thus a better tool over ANN.
\end{abstract}

Keywords: AI, ANFIS, ANN, ANFIS-AN, price prediction, Real Estate, Valuation

\footnotetext{
${ }^{1}$ A PhD candidate at Universiti Teknologi Malaysia Email: aayakubam@gmail.com
} 
PLANNING MALAYSIA

Journal of the Malaysia Institute of Planners (2021)

\section{INTRODUCTION}

Valuation of real estate is regularly required for distinctive investment purposes that could encompass valuation for mortgage lenders who require landed properties as collateral for securing advanced loans. Other uses of valuation reports include, premiums for insurance, rents and sales/purchase among others. Consequently, the need for accurate and dependable valuation figures, due to the fact a misguided investment valuation may have a devastating impact on investors who could require such financial valuation figures. In this line, many researchers have affirmed inconsistencies in many executed valuations as these figures, in most cases, do not represent market price (Abidoye \& Chan, 2017c; Ogunba \& Iroham, 2011). Such inconsistencies may arise as a result of negligence and biasness in the valuers' judgement (Mohammad et al., 2018) leading to dwindling of the valuers' image including liability for negligence (Atilola et al., 2019)

Therefore, there is the need to enhance the price prediction accuracy of real estate valuations considering the enormous capital tied in such investments, hence the application of Artificial Intelligent (AI) techniques in property valuation (Chaphalkar \& Sandbhor, 2013). Even though some specialists in the field may argue in opposition to the adoption of non-traditional valuation models, claiming that it cannot effectively substitute the conservative traditional techniques. Nevertheless, while this study is not calling for a total replacement of the traditional technique with AI, there is the need for having a complementary technique that would serve as a benchmark for the traditional technique. Hence, Mora-esperanza (2004) pronounced that the AI model best serves as an assisting tool to the valuers.

This study proposes the ANFIS-AN model which combines the ANN and ANFIS models, wherein the output arising from the ANFIS model becomes the ANN's input (figure 1.1). Thus, the projective ability of ANFIS-AN in real estate valuation was tested through a sizeable collection of experiments carried out with results indicating better performance by the proposed model over the baseline technique.

This article is organised into five steps. The first two-part deal with a background and a review of relevant literature. The next part is dedicated to the experimental setup for the study, while the fourth part presents the results and performance analysis of the advanced ANFIS-AN model. The final part concludes the findings of the study alongside recommending areas for further research. 
A. A. Yakub, Hishamuddin, Mohd. Ali, Kamalahasan, Achu, \& S.D Gimba

An Integrated Approach based on Artificial Intelligent using ANFIS and ANN for multiple criteria Real Estate Price Prediction

\section{RELATED RESEARCHES}

$\mathrm{AI}$ is seen as a method that is used by real estate operators in assessing market values through automatically capturing data having a causal relationship between value determinants and prices (Morano et al., 2003).

Popular amongst these AI techniques is the ANN technique modelled after the human neurological structure of the brain. ANN application in the realm of real estate valuation started in the '90s (Chan \& Abidoye, 2019).

Another related technique is the Fuzzy Neural network (FNN) which Kumari et al. (2013) describe as a hybrid neuro-fuzzy technique that combines the fuzzy structures' human-like reasoning alongside the learning and connection potential of the ANN to form a married model. Hence, FNN, in its architecture, forms a hybrid learning algorithm that adopts the IF-THEN rule capable of dealing with qualitative and quantitative information (İsen \& Boran, 2018). It is particularly useful as it replaces the crisp figures of the ANN where knowledge is stored in weight with MF found in FL technique which minimises the subjectivity tendencies of the valuers (Król et al., 2016). FNN is a useful resource in complex decisions due to its fast and accurate learning abilities alongside its good calibration and generalisation capacity (Yakubu \& Ziggah, 2017). This technique is sometimes referred to as the Neuro-Fuzzy System (NFS) or Adaptive Neuro-Fuzzy Inference System (ANFIS).

Among researchers that adopted AI techniques in real estate valuation includes those that applied only ANN in prediction (Abidoye \& Chan, 2017b; Rahman et al., 2019). Others compared the prediction ability of ANN with other techniques (Alexandridis et al., 2019; Cechin et al., 2000; Zurada et al., 2011). Others adopted fuzzy logic-FL (Gonzalez \& Formoso, 2006; Król et al., 2016; Pagourtzi et al., 2006) among others. On the other hand, are those that adopted a hybrid of ANN and FL to form ANFIS (Azadeh et al., 2014; Liu et al., 2006; Ustundag et al., 2011).

AI techniques are reported to have performed better, most especially in heterogeneous data sets (Zurada et al., 2011). Hence, some researchers reported that the performance of ANN is better than other methods (Abidoye et al., 2019; Mccluskey et al., 2013; Mimis et al., 2013). While, in comparing hybrid techniques to other models, it is affirmed that hybrid systems are better (Guan et al., 2008; Liu et al., 2006; Yacim \& Boshoff, 2020).

\section{EXPERIMENTAL SETUP}

This study adopts secondary class data from an online data bank ' 1 torgo, ${ }^{2}$ where 506 real estate transaction data sets were retrieved relating to real estate values in Boston. $49.7 \%$ of the data were screened out; hence, 255 data were randomly

\footnotetext{
${ }^{2}$ https://www.dcc.fc.up.pt/ ltorgo/Regression/housing.html 
selected. Adopting secondary data for statistical analysis using ANN is not unusual in literature, an example is the adoption of datasets from propertyGuru websites (Ke \& Wang, 2016); ingantlan ${ }^{3}$ (Kutasi \& Badics, 2016); and sahibiden ${ }^{4}$ (Kitapci et al., 2017). Others include Kaggle (Phan, 2019); stats $^{5}$ (Piao et al., 2019), while $\mathrm{Hu}$ et al. (2019) retrieved and adopted datasets from five foremost Chinese real estate secondary data sources ${ }^{6}$.

The adopted dataset 255 was fed into the proposed model, which is divided into two distinctive parts to include the ANN and ANFIS. The first stage of the prediction process was to train the dataset in the ANFIS model, the second stage was the adoption of the resultant output from the ANFIS model as the input datasets for the ANN model. This is demonstrated in figure 1.1 below;

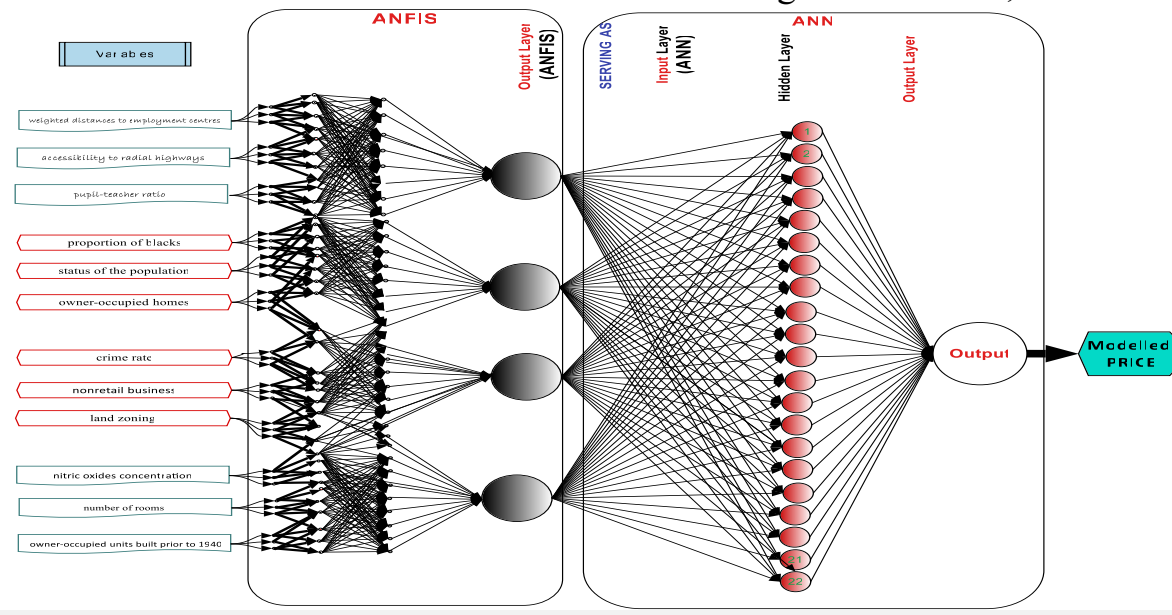

Figure 1.1ANFIS-AN architecture (the proposed model)

\section{Phase 1:The FNN model}

To achieve higher overall performance and attainment of a good generalisation potential, this study embraces the Gaussian MF. In specifying Membership Function (MF) parameters as it relates to fuzzy sets, the Bell and Gaussian types of MF remain the most adopted in literature as they have a non-zero point advantage with a robust smoothness alongside concise code. The Gaussian function is favoured in real estate application towards price determination (Liang et al., 2018).

\footnotetext{
${ }^{3}$ www.ingantlan.com

${ }^{4}$ www.sahibinden.com

${ }^{5} \mathrm{http}: / / \mathrm{www}$.stats.dl.gov.cn

${ }^{6}$ http://sz.ganji.com/fang1/, http://zu.anjuke.com/, http://sz.lianjia.com/zufang/, http://sz58.com/chuzu/, and http://www.sofang.com/esfrent/area/,
} 
A. A. Yakub, Hishamuddin, Mohd. Ali, Kamalahasan, Achu, \& S.D Gimba

An Integrated Approach based on Artificial Intelligent using ANFIS and ANN for multiple criteria Real Estate Price Prediction

Initially, $3 \mathrm{MF}$ was adopted, this was changed to 4 resulting in improved network performance, hence the MF was further adjusted to 5. Conversely, the network training confronted a critical delay when the MF changed into raised beyond 5, suggesting that it may cause a decline while raised further as cautioned by Guan et al. (2014) who acknowledged that continued surge in the MF might not necessarily further enhance the performance in the network.

In addition, other parameters were equally adjusted which includes the error goal and the epochs, which serves as a signal towards stopping the network. The network is programmed to end the training process, automatically, whenever either of these parameters is reached.

Twelve real estate price determinants serve as the input variables. The adopted number is justified as Mora-esperan (2004) whose study confirms that while the amount of input variables determines the number of input layers in a $\mathrm{NN}$, nonetheless between 10 to 50 variables is considered adequate when constructing a $\mathrm{NN}$ for use in property valuation.

Table 1.1:Summary of adopted parameters

\begin{tabular}{l|c|l|l|c}
\multicolumn{1}{c|}{ Parameter } & Value & & \multicolumn{1}{c|}{ Parameter } & Value \\
\cline { 1 - 2 } No. of fuzzy rules & 125 & & Nonlinear parameters & 30 \\
No. of training data pairs & 255 & & Linear parameters & 500 \\
No. of nodes & 286 & & Total number of parameters & 530 \\
Membership Function & 5 & & Epochs & 10 \\
\hline
\end{tabular}

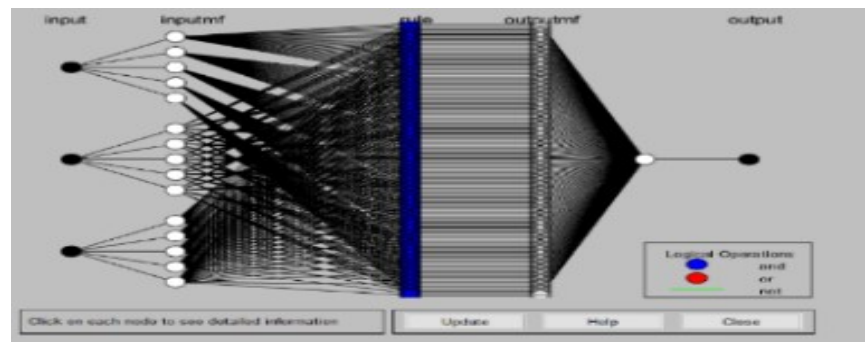

Figure 1.2The ANFIS network architecture (for a single group of 3 variables) Source: Data Analysis using Matlab R2019a

\section{Phase II:Input layers and Multi-Layer Perceptron (MLP)}

The screened 255 datasets were grouped into three sets namely 179 (training); 38 (testing); and 38 (validation) hence in ratio 70:15:15 in line with Chiarazzo et al. (2014). Even though, Chan \& Abidoye (2019) opined that the sharing of training cum testing ratio is at the discretion of the researcher, however, the study noted that a lesser portion is adequate for testing of the models.

Matlab R2019a was adopted in the training and testing procedure. This allows for flexibility of the network design and architecture; training benchmarks 
and simulation in design (Peterson \& Flanagan-III, 2009). Matlab R2019a also allows for a better and more efficient performing MLP (Al-Akhras \& Saadeh, 2010). MathWorks (2004) further uphold that the rule in the MLP perceptron learning is within the supervised learning classification.

\section{Determination of the number of hidden layers and neurons}

This study adopts a single hidden layered network. Lin \& Mohan (2011) recommend the adoption of a single hidden layer when modelling using MLP as a solitary hidden layer is sufficient in modelling a NN towards realizing accurate complex non-linear function. Hence, a single hidden layer node is considered adequate in a $\mathrm{NN}$ design for most practical problems (MathWorks, 2004).

However, in determining the number of neurons, otherwise term nodes, in a NN hidden layer, researchers including Limsombunchai (2004), Lin \& Mohan (2011) opine that experimentation, using trial and error, pending when a satisfactory result is achieved is recommended. Contrarily, Ge \& Runeson (2004) and Kitapci et al. (2017) stressed that determining the number of hidden neurons is crucial as it affects the convergence ability of the network, as insufficient hidden nodes disallow the feeding of the full specifics of the pattern involved in the NN leading to inability to converge. On the other hand, too many hidden layers often result to delay in the network and/or overtraining cum overfitting.

The above observations by different researchers affirm that caution needs to be taken in determining the number of neurons/nodes in a network's hidden layer. Thus, rather than the subjective random trial by error propounded by some researchers, Lam et al. (2008) and Abidoye et al. (2017) respectively explore the use of formula in their study as shown below;

1. $N_{h}=\frac{1}{2}$ (Inputs + Outputs) $+\sqrt{\text { Number of patterns in the training file }}$ eqn. 2

2. $N_{h}=\frac{N_{\text {in }}+N_{\text {out }}}{2}+\sqrt{N_{s}}$ eqn.3

$\mathrm{N}_{\mathrm{h}}$ implies the number of neurons adaptable in a hidden layer. $\mathrm{N}_{\mathrm{in}}$ signifies the input while $\mathrm{N}_{\text {out }}$ indicates the output layer and $\mathrm{N}_{\mathrm{s}}$ indicates the training samples.

Therefore, this study adopt MLP using the supervised learning rule. Hence, different $\mathrm{NN}$ topologies were applied, with adjustments, to the hidden neurons during the network's learning process ranging from 16-22 neurons while seeking the most appropriate network. However, more concentration was centred on having neurons within the group 20-24 because when the parameters were applied to the formula, $N_{h}$ indicated 22.9687. Nevertheless, when subjected to several trials, the study's best-performing architecture contains 22 hidden neurons resulting in an architecture of 12:22:1. The results of these trials are given in tables 1.2 and 1.3 below. 
A. A. Yakub, Hishamuddin, Mohd. Ali, Kamalahasan, Achu, \& S.D Gimba

An Integrated Approach based on Artificial Intelligent using ANFIS and ANN for multiple criteria Real Estate Price Prediction

Table 1.2: Trained MSE results for both ANN and ANFIS-AN

\begin{tabular}{|c|c|c|c|c|}
\hline Number of nodes & & & ANFIS-AN & ANN \\
\hline 16 & & & 2.91 & 5.07 \\
\hline 19 & & & 3.25 & $1.74 \mathrm{e}-6$ \\
\hline \multirow{5}{*}{22} & \multirow{5}{*}{ 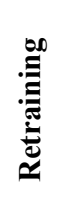 } & $1^{\text {st }}$ & 1.40 & $7.76 \mathrm{e}-7$ \\
\hline & & $2^{\text {nd }}$ & 1.35 & $6.38 \mathrm{e}-8$ \\
\hline & & $3^{\text {rd }}$ & 2.01 & $3.53 \mathrm{e}-11$ \\
\hline & & $4^{\text {th }}$ & 14.81 & $2.49 \mathrm{e}-9$ \\
\hline & & $5^{\text {th }}$ & 4.91 & $2.81 \mathrm{e}-8$ \\
\hline
\end{tabular}

Table 1.3: Tested MSE results for both ANN and ANFIS-AN

\begin{tabular}{|c|c|c|c|c|}
\hline Number of nodes & & & ANFIS-AN & ANN \\
\hline 16 & & & 32.20 & 1482.72 \\
\hline 19 & & & 12.94 & 314.26 \\
\hline \multirow{5}{*}{22} & \multirow{5}{*}{ 苞 } & $1^{\text {st }}$ & 7.96 & 519.51 \\
\hline & & $2^{\text {nd }}$ & 5.66 & 781.86 \\
\hline & & $3^{\text {rd }}$ & 114.47 & 663.31 \\
\hline & & $4^{\text {th }}$ & 13.15 & 1014.18 \\
\hline & & $5^{\text {th }}$ & 9.82 & 1617.22 \\
\hline
\end{tabular}

\section{Training of the network}

The ANFIS model was adopted in the first segment in the ANFIS-AN model, while the ANN was adopted in the second segment. In the $1^{\text {st }}$ segment, the input nodes were divided into 4 groups, hence each group had 3 nodes making 12 nodes in total, generating 4 output neurons in total. This is consistent with past researches such as Ustundag et al. (2011); Khoshnevisan et al. (2014); Gerami Moghadam et al. (2019) among others. The best outcome was attained when 3 inputs were adopted at each stage; gaussmf was used for the input MF function while linear was adopted for the output MF function; and adoption of a 5 number MF at 10 epoch for the four groups.

These output neurons from the ANFIS were thereafter fed into the ANN model serving as its inputs, which were yet again retrained using one single hidden layer with 22 nodes to yield the final resultant output of the ANFIS-AN model.

A feedforward backpropagation algorithm was implemented in training each of the ANN and $2^{\text {nd }}$ segment of the ANFIS-AN architectural structure to model the relationship among the variables (input), and the target price (output). The parameters involving the epochs and number of hidden neurons were sufficiently adjusted using trial and error to reduce the prediction errors at the training, testing and validation phases. This is consistent with past researchers as Mora-esperanza (2004) opined that ANN does not provide the requisite number of outputs during the first trial, rather until after undergoing adequate training, as 
they are required to learn, thus the need for subjecting the $\mathrm{NN}$ to successive trial and error sessions. This viewpoint was further buttressed in Eriki \& Udegbunam (2008), the study stressed that modifications are required in NN parameters involving model specification; training cycles and the number of hidden neurons in realizing the best outcome in a NN. These adjustments in the learning rate and momentum are attainable through trial and error.

This study further adopted trainlm (lavernberg-Marquardt) in training the NN, although trainlm is the time taken, nevertheless, the algorithm is capable of attaining good generalisation. On the other hand, this study adopts learngm as the learning function for the $\mathrm{NN}$, while the performance function adopted is the Mean Squared Error (MSE), which is in line with Hegde (2018).

\section{RESULTS AND PERFORMANCE EVALUATION}

\section{Training and Retraining sessions}

Three different $\mathrm{NN}$ topologies were trained adopting 12 input variables in addition to 1-output variables using several parameters for the hidden neurons. The network architecture of 12:22:1 achieved the best performance; this same structure was adopted for the proposed ANFIS-AN model for a simple comparison of their final result.

The training of both models was carried out in three dynamic stages. 16 neurons were adopted in the first stage, and this stage produced the best outcome for the proposed ANFIS-AN model over the ANN model. These numbers of neurons were increased to 19 in the second stage. The results of the second stage training session showed that ANN performed better, whereas the testing session exhibited a better result for ANFIS-AN. Nevertheless, it should be noted that the most crucial phase of a NN's learning session is the testing stage as the trained network becomes capable of adopting the learning parameters that it gained during the training sessions towards predicting the prices of untrained variables.

In the third stage of the training and testing session, the number of neurons was raised to 22 in line with the results of the formula for estimating the number of the hidden neuron as shown in equations 2 and 3 above. The results from this stage became the best of the three stages adopted, hence the bestperforming architecture for the ANFIS-AN model.

Thereafter, the network was subjected to retraining five different times using the same parameter to further assess its efficiency ability. During each of these retraining sessions, all training sessions in the ANN model demonstrated good learning ability, hence a better training technique over the proposed model. However, in terms of testing, the ANFIS-AN tests demonstrated better results over that of ANN which indicates its ability to yield better results whenever it is used in predicting new untrained datasets. 
A. A. Yakub, Hishamuddin, Mohd. Ali, Kamalahasan, Achu, \& S.D Gimba

An Integrated Approach based on Artificial Intelligent using ANFIS and ANN for multiple criteria Real Estate Price Prediction

\section{Error testing models}

Comparisons were made between the performance of the proposed ANFISAN and the ANN models using mean squared error (MSE) that was automatically produced from Matlab's toolbox. To further test the prediction capability of both methods, an additional 2 error measuring techniques were adopted to include the mean absolute percentage error (MAPE) and the root mean squared error (RMSE) as shown in table 1.4;

Table 1.4: Error testing performance of ANN and ANFIS-AN models

\begin{tabular}{lccc} 
Error Model & ANFISA & ANN & Model v ANN (\% lower) \\
\hline MSE & 1.997046 & 98.84747 & -4849.68 \\
\hline RMSE & 1.413169 & 9.942206 & -603.54 \\
\hline MAPE & 0.208324 & 0.256438 & -23.0955 \\
\hline
\end{tabular}

The performance of the models as shown in table 1.4 above signify that the proposed model which combines ANFIS with ANN as a single model where the consequential outputs of the ANFIS model are fed into the ANN network model serving as inputs. The model performed better and more accurate using all the error-measuring models in predicting the price of the 255 sampled real estate.

\section{CONCLUSION AND FURTHER RESEARCH}

In conclusion, a proposed model that combines ANFIS and ANN models into a single model was adopted in price prediction of 255 sampled real estates using Matlab R2019a and network architecture of 12:22:1 and a ration 70:15:15 for training, testing and validation respectively. Thereafter, three error-testing models were adopted in comparing the performance of both the ANN and ANFIS-AN model. The results show that the proposed hybrid model, ANFISAN's performance is better and more robust with a notable high forecasting accuracy over the ANN model. Hence, this study confirms the fact that fashioning a tutelage of the methods is capable of fortifying nonlinear models thereby resulting in the sophistication of the real estate price prediction model.

Consequently, its acceptance in real estate valuation practice is expected to improve the predictability of values cum prices, thus guiding practitioners and investors alike including a handful of contributions to the existing body of knowledge in AI application to real estate price prediction.

Finally, further research is feasible in the areas of adopting primary data sources in real estate price prediction in developing nations using ANFIS-AN model. Consequently, in furthering this research, the proposed model, ANFISAN, will be implemented in modelling commercial real estate prices for the northern part of Nigeria. 
PLANNING MALAYSIA

Journal of the Malaysia Institute of Planners (2021)

\section{ACKNOWLEDGEMENT}

The authors acknowledge the efforts of the National Real Estate Research Coordinator (NAPREC) Grant that sponsored this research.

\section{REFERENCES}

Abidoye, R. B., \& Chan, A. P. C. (2017a). Artificial neural network in property valuation: application framework and research trend. Property Management, 35(5), 554 571. https://doi.org/10.1108/PM-06-2016-0027

Abidoye, R. B., \& Chan, A. P. C. (2017b). Modelling property values in Nigeria using artificial neural network. Journal of Property Research, 9916, 0. https://doi.org/10.1080/09599916.2017.1286366

Abidoye, R. B., \& Chan, A. P. C. (2017c). Valuers' receptiveness to the application of artificial intelligence in property valuation. Pacific Rim Property Research Journal, 23(2), 175-193. https://doi.org/10.1080/14445921.2017.1299453

Abidoye, R. B., Chan, A. P. C., Abidoye, F. A., \& Oshodi, O. S. (2019). Predicting property price index using artificial intelligence techniques: Evidence from Hong Kong. International Journal of Housing Markets and Analysis, 12(6), 1072-1092. https://doi.org/10.1108/IJHMA-11-2018-0095

Al-Akhras, M., \& Saadeh, M. (2010). Automatic valuation of Jordanian estates using a genetically-optimised Artificial Neural Network approach. WSEAS Transactions on Systems, 9(8), 905-915.

Alexandridis, A. K., Karlis, D., Papastamos, D., \& Andritsos, D. (2019). Real Estate valuation and forecasting in non-homogeneous markets: A case study in Greece during the financial crisis. Journal of the Operational Research Society, 70(10), 1769-1783. https://doi.org/10.1080/01605682.2018.1468864

Atilola, M. I., Ismail, A., Achu, K., \& Bujang, A. A. (2019). An evaluation of factors causing variance in property assessment. Planning Malaysia, 17(1), 82-93. https://doi.org/10.21837/pmjournal.v17.i9.588

Azadeh, A., Sheikhalishahi, M., \& Boostani, A. (2014). A flexible neuro-fuzzy approach for improvement of seasonal housing price estimation in uncertain and non-linear environments. South African Journal of Economics, 82(4), 567-582.

Cechin, A. L., Souto, A., \& González, M. A. (2000). Real Estate Value at Porto Alegre City Using Artificial Neural Networks. Vol.1., Sixth Brazilian Symposium on Neural Networks, 237-242. https://doi.org/10.1109/SBRN.2000.889745

Chan, A. P. C., \& Abidoye, B. R. (2019). Advanced Property Valuation Techniques and Valuation Accuracy: Deciphering the Artificial Neural Network Technique. International Journal of Real Estate and Land Planning, 2, 2623-4807.

Chaphalkar, N. B., \& Sandbhor, S. (2013). Use of Artificial Intelligence in Real Property Valuation. 5(3), 2334-2337.

Chiarazzo, V., Caggiani, L., Marinelli, M., \& Ottomanelli, M. (2014). A neural network based model for real estate price estimation considering environmental quality of property location. Transportation Research Procedia, 3(July), 810-817.

Eriki, P. O., \& Udegbunam, R. I. (2008). Application of Neural Network in evaluating Prices of Housing units in Nigeria: a preliminary investigation. Journal of 
A. A. Yakub, Hishamuddin, Mohd. Ali, Kamalahasan, Achu, \& S.D Gimba

An Integrated Approach based on Artificial Intelligent using ANFIS and ANN for multiple criteria Real Estate

Price Prediction

Artificial Intelligence, 1(1), 21-27. https://doi.org/10.3923/jai.2008.21.27

Ge, X. J. (2004). Modeling Property Prices Using Neural Network Model for Hong Kong. 7(1), 121-138.

Gerami Moghadam, R., Yaghoubi, B., Izadbakhsh, M. A., \& Shabanlou, S. (2019). Prediction of the hydraulic jump length on sloping rough beds using metaheuristic neuro-fuzzy model and differential evolution algorithm. Journal of Applied Research in Water and Wastewater, 6(1), 8-15. https://doi.org/10.22126/arww.2019.1019

Gonzalez, M. A. S., \& Formoso, C. T. (2006). Mass appraisal with genetic fuzzy rulebased systems. Property Management, 24(1), 20-30. https://doi.org/10.1108/02637470610643092

Guan, J., Shi, D., Zurada, J. M., \& Levitan, A. S. (2014). Analyzing Massive Data Sets: An Adaptive Fuzzy Neural Approach for Prediction, with a Real Estate Illustration. Journal of Organizational Computing and Electronic Commerce, 24(1), 94-112. https://doi.org/10.1080/10919392.2014.866505

Guan, J., Zurada, J., \& Levitan, A. S. (2008). An adaptive neuro-fuzzy inference system based approach to real estate property assessment. Journal of Real Estate Research, 30(4), 395-422.

Hegde, M. N. (2018). Comparison of Artificial Neural Networks and Fuzzy Logic approaches for crack detection in a beam like structure. International Journal of Artificial Intelligence and Applications (IJAIA), 9(1), 35-51. https://doi.org/DOI : 10.5121/ijaia.2018.9103

Hu, L., He, S., Han, Z., Xiao, H., Su, S., Weng, M., \& Cai, Z. (2019). Monitoring housing rental prices based on social media:An integrated approach of machine-learning algorithms and hedonic modeling to inform equitable housing policies. Land Use Policy, 82(129), 657-673. https://doi.org/10.1016/j.landusepol.2018.12.030

İsen, E., \& Boran, S. (2018). A Novel Approach Based on Combining ANFIS, Genetic Algorithm and Fuzzy c-Means Methods for Multiple Criteria Inventory Classification. Arabian Journal for Science and Engineering, 43(6), 3229-3239.

Ke, Q., \& Wang, W. (2016). The factors that determine shopping centre rent in Wuhan, China. Journal of Property Investment and Finance, 34(2), 172-185. https://doi.org/10.1108/JPIF-04-2015-0021

Khoshnevisan, B., Rafiee, S., Omid, M., \& Mousazadeh, H. (2014). Development of an intelligent system based on ANFIS for predicting wheat grain yield on the basis of energy inputs. Information Processing in Agriculture, 1(1), 14-22. https://doi.org/10.1016/j.inpa.2014.04.001

Kitapci, O., Tosun, Ö., Tuna, M. F., \& Turk, T. (2017). The Use of Artificial Neural Networks (ANN) in Forecasting Housing Prices in Ankara, Turkey. Journal of Marketing and Consumer Behaviour in Emerging Markets, 2017(5), 4-14. https://doi.org/10.7172/2449-6634.jmcbem.2017.1.1

Król, D., Lasota, T., Trawiński, B., \& Trawiński, K. (2016). Investigation of evolutionary optimization methods of TSK fuzzy model for real estate appraisal. International Journal of Hybrid Intelligent Systems, 5(3), 111-128.

Kumari, N., Sunita, \& Smita. (2013). Comparison of ANNs, Fuzzy Logic and NeuroFuzzy Integrated Approach for Diagnosis of Coronary Heart Disease: A Survey. 
International Journal of Computer Science and Mobile Computing (IJCSMC), 2(6), 216-224.

Kutasi, D., \& Badics, M. C. (2016). Valuation Methods for the Housing Market: evidence from Budapest. Acta Oeconomica, 66(3), 527-546.

Lam, K. C., Yu, C. Y., \& Lam, K. Y. (2008). An artificial neural network and entropy model for residential property price forecasting in Hong Kong. Journal of Property Research, 25(4), 321-342. https://doi.org/10.1080/09599910902837051

Liang, X., Liu, Y., Qiu, T., Jing, Y., \& Fang, F. (2018). The effects of locational factors on the housing prices of residential communities: The case of Ningbo, China. Habitat International, 81(August), 1-11. https://doi.org/10.1016/j.habitatint.2018.09.004

Limsombunchai, V., Gan, C., Lee, M., Box, P. O., \& Zealand, N. (2004). House Price Prediction: Hedonic Price Model vs Artificial Neural Network. American Journal of Applied Sciences, 3(1), 193-201. https://doi.org/10.3844/ajassp.2004.193.201

Lin, C. C., \& Mohan, S. B. (2011). Effectiveness comparison of the residential property mass appraisal methodologies in the USA. International Journal of Housing Markets and Analysis, 4(3), 224-243. https://doi.org/10.1108/17538271111153013

Liu, J., Zhang, X., \& Wu, W. (2006). Application of Fuzzy Neural Network for Real Estate Prediction. International Symposium on Neural Networks; Advances in Neural Networks, 1187-1191.

MathWorks, I. (2004). Neural network toolbox ${ }^{\mathrm{TM}}$ For Use with MATLAB. In H. Demuth, M. Beale, \& M. Hagan (Eds.), User's guide (4th ed.).

Mccluskey, W. J., Mccord, M., Davis, P. T., Haran, M., Mcilhatton, D., Mccord, M., Davis, P. T., Haran, M., \& Mcilhatton, D. (2013). Prediction accuracy in mass appraisal : a comparison of modern approaches. Journal of Property Research ISSN:, 30(4), 239-265. https://doi.org/10.1080/09599916.2013.781204

Mimis, A., Rovolis, A., \& Stamou, M. (2013). Property valuation with artificial neural network: The case of Athens. Journal of Property Research, 30(2), 128-143.

Mohammad, N. E., Ali, H. M., \& Jasimin, T. H. (2018). Valuer's behavioural uncertainties in property valuation decision making. Planning Malaysia, 16(1), 239-250.

Mora-esperanza, J. G. (2004). Artificial Intelligence Applied to Real Estate Valuation; an example for the appraisal of Madrid. CATASTRO, 1(April), 255-265.

Morano, P., Tajani, F., \& Torre, C. M. (2003). Artificial intelligence in property valuations An application of artificial neural networks to housing appraisal. Advances in Environmental Science and Energy Planning, 2015, 23-29.

Ogunba, A. O., \& Iroham, C. O. (2011). A search for an acceptable margin of valuation error: A case study of valuers and their clients in Nigeria. Sri Lanka Journal of Real Estate, 1(4), 54-73.

Pagourtzi, E., Nikolopoulos, K., \& Assimakopoulos, V. (2006). Architecture for a real estate analysis information system using GIS techniques integrated with fuzzy theory. Journal of Property Investment and Finance, 24(1), 68-78.

Peterson, S., \& Flanagan-III, A. B. (2009). Neural Network Hedonic Pricing Models in Mass Real Estate Appraisal. Journal of Real Estate Research, American Real 
A. A. Yakub, Hishamuddin, Mohd. Ali, Kamalahasan, Achu, \& S.D Gimba

An Integrated Approach based on Artificial Intelligent using ANFIS and ANN for multiple criteria Real Estate

Price Prediction

Estate Society, 31(2), 147-164.

Phan, T. D. (2019). Housing price prediction using machine learning algorithms: The case of Melbourne city, Australia. Proceedings - International Conference on Machine Learning and Data Engineering, ICMLDE 2018, 8-13.

Piao, Y., Chen, A., \& Shang, Z. (2019). Housing Price Prediction Based on CNN. 9th International Conference on Information Science and Technology, ICIST 2019, 491-495. https://doi.org/10.1109/ICIST.2019.8836731

Rahman, S. N. A., Maimun, N. H. A., Razali, M. N., \& Ismail, S. (2019). The artificial neural network model (ANN) for Malaysian housing market analysis. Planning Malaysia, 17(1), 1-9. https://doi.org/10.21837/pmjournal.v17.i9.581

Ustundag, A., Cevikcan, E., \& Kilinc, M. S. (2011). A hybrid fuzzy risk evaluation model for real estate investments. Journal of Multiple-Valued Logic and Soft Computing, 17(4), 339-362.

Yacim, J. A., \& Boshoff, D. G. B. (2020). Neural networks support vector machine for mass appraisal of properties. Property Management, 38(2), 241-272.

Yakubu, I., \& Ziggah, Y. Y. (2017). Appraisal of ANN and ANFIS for Predicting Vertical Total Electron Content (VTEC) in the Ionosphere for GPS Observations. Ghana Mining Journal, 17(2), 12-16.

Zurada, J., Levitan, A. S., \& Guan, J. (2011). A comparison of regression and artificial intelligence methods in a mass appraisal context. Journal of Real Estate Research, 33(3), 349-387.

Received: $12^{\text {th }}$ July 2021. Accepted: $23^{\text {rd }}$ Sept 2021 